\title{
ESTADO DE COSAS INCONSTITUCIONAL EN \\ COLOMBIA: UNA APROXIMACIÓN JURÍDICA A UN ELEMENTO DECISIONAL
}

\author{
ESTADO DE COISAS INCONSTITUCIONAL NA COLÔMBIA: UMA ABORDAGEM \\ JURÍDICA A UM ELEMENTO DECISIONAL
}

UNCONSTITUTIONAL STATE OF AFFAIRS IN COLOMBIA: A LEGAL APPROACH TO A

DECISION-MAKING ELEMENT

Licença CC BY:

Artigo distribuído sob os termos Creative Commons, permite uso e distribuição irrestrita em qualquer meio desde que o autor credite a fonte original.

\section{Milton César Jiménez Ramírez}

La puerta que da a la ley está abierta, como de costumbre; cuando el guardián se hace a un lado, el hombre se inclina para espiar. El guardián lo ve, se ríe y le dice: Si tanto es tu deseo, haz la prueba de entrar a pesar de mi prohibición. Pero recuerda que soy poderoso. Y sólo soy el último de los guardianes. Entre salón y salón también hay guardianes, cada uno más poderoso que el otro. Ya el tercer guardián es tan terrible que no puedo soportar su aspecto².

Resumen: Este escrito tiene por objeto presentar una aproximación a los principales componentes jurisprudenciales que definen y hacen aplicable el instrumento judicial del ECI. Al efecto, el tema se desarrollará en cuatro partes. Una primera parte, en la que se hará una aproximación al concepto jurídico o elementos definitorios del $\mathrm{ECl}$; una segunda, en la que expondrán los elementos necesarios para que pueda procederse a su declaración judicial; en la tercera parte se harán algunas consideraciones respecto del caso hito del desplazamiento forzado interno; y en la cuarta se hará un análisis acerca del instrumento de evaluación de la superación del ECl. Finalmente, se presentarán varias conclusiones sobre el tema examinado.

Palabras clave: Componentes jurisprudenciales; Estado de cosas inconstitucional; Declaración judicial

Resumo: Este artigo pretende apresentar uma abordagem dos principais componentes jurisprudenciais que definem e tornam aplicável o instrumento judicial da $\mathrm{ECI}$ (Estado de Coisas Inconstituciuonais). Para esse fim, o tema será desenvolvido em quatro partes. Na primeira parte, será feita uma abordagem ao

$1 \quad$ Abogado por la Universidad de Caldas, Especialista en Derecho Constitucional de la Universidad Nacional de Colombia, Magister en Derecho Público por la Universidad Externado de Colombia; Doctor en Derecho (Universidad Carlos III de Madrid). Doctorando en Derecho (Universidad de Alicante); docente investigador del Programa de Derecho y el Departamento de Jurídicas de la Facultad de Ciencias Jurídicas y Sociales de la Universidad de Caldas. Director del grupo de investigación Poderes Públicos. ORCID 0000-0003-1149-4723. milton.jimenez@ucaldas.edu. CO 


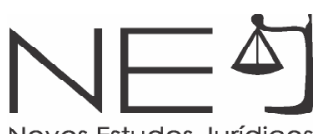

conceito jurídico ou aos elementos definidores da $\mathrm{ECl}$; na segunda, serão apresentados os elementos necessários para prosseguir com sua declaração judicial; na terceira parte, serão consideradas algumas considerações sobre o caso marcante do deslocamento interno forçado; e no quarto, será feita uma análise sobre o instrumento para avaliar a melhoria do ECI. Por fim, serão apresentadas várias conclusões sobre o assunto examinado.

Palavras chaves: Componentes jurisprudencias; Estado de coisas inconstitucional; Declaração judicial.

Abstract: This work aims to present an approach to the main jurisprudential component that define and make applicable the judicial instrument of the Unconstitutional State of Affairs [Estado de Coisas Inconstitucional] $(\mathrm{ECl})$. The theme is developed in four parts. The first part addresses the legal concept or the elements that define the $\mathrm{ECl}$. The second part describes the elements necessary to carry out the legal statement. The third gives some considerations on the case of forced internal displacement; and the fourth analyzes the assessment tool for overcoming ECl. The final part gives some conclusions on the theme examined.

Keywords: jurisprudential components; Unconstitutional State of Affairs; Legal Statement.

\section{INTRODUCCIÓN}

Pensar en una figura mediante la cual el juez constitucional pueda desarrollar con mayor fortaleza su rol de garante de los derechos fundamentales frente a situaciones que desconozcan la fuerza normativa y la supremacía de la Constitución ${ }^{3}$, es ineludible en estados y sistemas jurídicos en lo que sea imperativo la prevalencia de los derechos de la población más débil o vulnerable; en los que sea exigible una actuación protectora y consciente de las libertades y la humanidad por parte de los poderes públicos, e incluso de los privados ${ }^{4}$. La protección de la población más necesitada es un aspecto central en la búsqueda de la civilidad, así como en la consolidación de la democracia y del Estado Social ${ }^{5}$, pues aquellos que poseen carencias extremas se encuentran privados de sus capacidades básicas ${ }^{6}$, lo que impide que ejerzan su libertad y a la par profundiza su exclusión sumiéndolos a un apartheid ${ }^{7}$.

La figura reclamada es la denominada estado de cosas inconstitucional (ECI), la cual puede entenderse como una declaración judicial capaz de acumular una serie de hechos masivos, notorios y persistentes y en todo caso contrarios a las directrices y axiología constitucionales. Se trata de una figura jurisprudencial que evalúa diversas realidades infractoras de la Constitución, exigiendo su corrección integral no solo por intermedio de una decisión judicial, sino ordenando la participación de las distintas entidades estatales a través del cumplimiento de las funciones que les son propias; en otros términos, promoviendo la colaboración armónica entre las ramas del poder público.

3 HESSE, K. Escritos de Derecho Constitucional. Madrid, España: Centro de Estudios Constitucionales, 1983.

4 BÖCKENFÖRDE, E. W. Escritos sobre derechos fundamentales. Baden-Baden, Alemania: Nomos Verlagsgesellschaft, 1993.

5 La protección de las minorías, de los más débiles y de la prevalencia de la dignidad humana hacen parte de las exigencias fundamentales de la cláusula del Estado Social de Derecho, como principio esencial o insustituible, que debe guiar la gestión de toda autoridad pública, bien los jueces como garantes de los derechos constitucionales, bien el legislador y el ejecutivo como responsables del servicio público.

6 SEN, A. Desarrollo y Libertad. Bogotá: Editorial Planeta, 2001. p.116-117.

7 GARCÍA, M.;ESPINOSA, J. EI Derecho al Estado. Los Efectos Legales del Apartheid Institucional en Colombia. Bogotá: Centro de Estudios de Derecho, Justicia y Sociedad DeJuSticia, 2013, p.146 y sig. 
Dadas las cosas, este escrito tiene por objeto presentar una aproximación a los principales componentes jurisprudenciales que definen y hacen aplicable el instrumento judicial del ECI. Al efecto, el tema se desarrollará en cuatro partes. Una primera parte, en la que se hará una aproximación al concepto jurídico o elementos definitorios del ECl; una segunda, en la que expondrán los elementos necesarios para que pueda procederse a su declaración judicial; en la tercera parte se harán algunas consideraciones respecto del caso hito del desplazamiento forzado interno; y en la cuarta se hará un análisis acerca del instrumento de evaluación de la superación del ECl. Finalmente, se presentarán varias conclusiones sobre el tema examinado.

\section{UNA APROXIMACIÓN A LA DEFINICIÓN DEL ESTADO DE COSAS INCONSTITUCIONAL APROXIMACIÓN A UN CONCEPTO CONSTITUCIONAL}

El ECl es una declaración judicial, particularmente de la Corte Constitucional, con la que se pretende sancionar hechos persistentes, masivos y notorios que contradicen de forma grave la Constitución, desconociendo su primacía, fuerza normativa y la prevalencia de la dignidad humana; los hechos que ordinariamente lo fomentan son infracciones contra los derechos fundamentales de las personas en condiciones de debilidad manifiesta o vulnerabilidad ${ }^{8}$, o que revierten los valores y directrices constitucionales y en consecuencia del Estado Social de Derecho.

Cabe decir que el ECI es una respuesta judicial a hechos de gran impacto social, amparada en el rol que como garante y máximo intérprete constitucional posee el juez; su declaración surge de un caso concreto pero la decisión tiene efectos generales, no simplemente interpartes, con el fin de vincular como responsables totales, parciales o conjuntos a diversas entidades estatales. Para ofrecer una protección integral a la violación masiva de derechos, y no perpetuar el estado de desigualdad e indignidad que en un determinado evento se pueda presentar, la declaración puede exigir la creación de políticas públicas que permitan responder de forma directa y progresiva a la situación que se quiere rebatir hasta que se declare como superado el $\mathrm{ECl}$.

Lo anterior supone que desde lo jurídico se pretende adoptar decisiones interdisciplinarias e interinstitucionales con el fin de priorizar la reparación de los derechos, impedir la perpetuación de amenazas, acciones u omisiones infractoras de la Constitución. Toda la actuación judicial y la

8 Al respecto, ver: Sentencias T-602/03 y T-721/03. En estas sentencias se reconoce la condición de debilidad manifiesta para los desplazados, para quienes poseen una afectación de su mínimo vital, para los campesinos, para los afectados psicológicamente por el conflicto, a las mujeres, los despojados de su vivienda y tierra, los marginados, enfermos, los desprovisto del mínimo alimentario, la desarticulación social. Lo que muestra el necesario entendimiento de la debilidad manifiesta o de la vulnerabilidad en un caso concreto desde circunstancias materiales, conscientes de la dignidad humana, lo territorial y del género. A esta enunciación debe complementarse la descripción constitucional que incluye a los menores de edad (art. 44); las mujeres gestantes y lactantes, las madres y padres cabeza de familia (arts. 42 y 43 ); las personas de la tercera edad (art. 46); los discapacitados (art. 47); las minorías étnicas; las personas privadas de la libertad, los secuestrados, las personas en condiciones de pobreza extrema, las personas con condiciones sexuales diversas, y cualquier persona que sufra la discriminación por criterios sospechosos de clasificación. COLOMBIA. Corte constitucional. Disponible en: https://www.corteconstitucional.gov.co/T-025-04/ A2014.php. Consultado el 19 oct. 2019. 
declaración del ECl estará fundamentada en la falta de imputación de los hechos a la Constitución, tal como si se tratará del juicio de constitucionalidad de una norma que no es adecuada o regular frente a la norma superior, generando su expulsión del sistema jurídico, que no pueda ser aceptada o concebida como derecho9 . Se homologan los hechos a la norma para proceder a declarar su inconstitucionalidad, pues es la facticidad concreta la que genera la infracción masiva de los principios y valores constitucionales. Lo que hace que los jueces promuevan que la Constitución adopte una mayor potencia normativa, no solo regulativa de un pueblo determinado, sino de la realidad misma.

Existen eventos en que la realidad modifica o reforma la Constitución sin apelar a sus mecanismos de reforma, lo que mengua la fuerza normativa de la Constitución ${ }^{10}$, tal es el caso de la mutación constitucional; empero en el ECl estamos en presencia de un fenómeno jurídico inverso, se confrontan los hechos para que se adecúen progresivamente a la norma constitucional, como referente político y social. Puede soportar este análisis lo planteado por el Tribunal Constitucional en la Sentencia T-215/02 ${ }^{11}$, cuando aborda el caso del desplazamiento:

El conflicto...que deja como secuela el desplazamiento de miles de colombianos que se ven forzados a unas condiciones de vida que son la negación del constitucionalismo pues, entre más se intensifica el conflicto interno, menos posibilidades tienen de que en su favor se realicen los derechos reconocidos en ese acuerdo. Surge así una evidente tensión entre la pretensión de organización política y la prolífica declaración de valores, principios y derechos contenidas en el Texto Fundamental y la diaria y trágica constatación de la exclusión de ese acuerdo de millones de colombianos: El estado de desplazamiento forzado en que se hallan contraría la racionalidad implícita en el constitucionalismo como alternativa de vida civilizada.

Esto también significa que la Constitución es interpretada como criterio de justicia, como parámetro de corrección, como soporte de la vigencia de los principios liberal, democrático y social. Y, a la par, como baluarte de legitimidad para que los jueces constitucionales puedan declarar la existencia de un estado de cosas y ordenar a las demás ramas del poder público, órganos de control y demás organismos estatales una actuación consecuente con sus deberes constitucionales ${ }^{12}$ y la moralidad administrativa ${ }^{13}$; sin embargo, esto no implica que se trate de una cuestión totalmente aceptada o armoniosa, ya que la decisión judicial puede ser vista como una intromisión indebida en

$9 \quad$ KELSEN, Hans. La Garantía Jurisdiccional de la Constitución. Revista Iberoamericana de Derecho Procesal Constitucional, 2008, v. 10. 3-46.

10 HABERLE, P. El Estado Constitucional. Ciudad de México: Universidad Autónoma de México, 2003.

11 Ver Sentencias SU-1150/00, T-1346/01 y T-268/03. COLOMBIA. Corte constitucional. Disponible en: https://www.corteconstitucional.gov.co/T025-04/A2014.php. Consultado el 19 oct. 2019.

12 La realidad que supone el ECI pone en cuestión la función de garantías del Estado, que es uno de sus fundamentos de existencia, y promoviendo una Constitución de papel, pues las autoridades no cumplen aquello para lo que están instituidas: proteger a todas las personas residentes en Colombia y para asegurar el cumplimiento de los deberes sociales del Estado (Const., 1191, art. 2), lo que al no cumplirse se convierte en una infracción estructural reparable por una sentencia de igual calidad. LASALLE, F. J. G. ¿Qué es una Constitución?. Bogotá: Editorial Temis, 2010.

13 La moralidad administrativa como derecho colectivo supone que las autoridades públicas deben actuar con plena probidad en el cumplimiento de los fines que les han sido encomendados, siguiendo los principios constitucionales de la función pública (Const., 1991, art. 209) y la colaboración armónica entre los poderes públicos (Const., 1991, art. 113). COLOMBIA. Constitución política de Colombia 1991. Disponible en: https://www.corteconstitucional.gov.co/inicio/Constitucion\%20politica\%20de\%20Colombia.pdf. 
las competencias de los demás poderes públicos y como una extralimitación de los poderes de tutela de los derechos fundamentales y defensa de la Constitución, lo que desencadena justamente en el desconocimiento de un pilar constitucional como la separación de poderes.

Es justamente en tal dilema que se pueden encontrar los primeros referentes del ECl, principalmente en las figuras de la political question doctrine y structural remedies.

\section{UNA BREVE REFERENCIA A LOS ORÍGENES DEL ESTADO DE COSAS INCONSTITUCIONAL}

La figura del $\mathrm{ECl}$ tuvo uno de sus principales referentes históricos en el derecho americano ${ }^{14}$, en las figuras de la political question doctrine y structural remedies, que sirvieron a la Corte Constitucional para su fundamentación y uso jurisprudencial ${ }^{15}$. Así, en la figura de la political question doctrine se restringe la posibilidad de una intervención judicial, pese a que se alegue que el juez está amparado en la necesidad de velar por la defensa y aplicación de la Constitución, ya que no se concibe un llamamiento a la rama ejecutiva y judicial, pues se confía en que actúen bajo sus precisas funciones (principio de legalidad) y autonomía (separación de poderes).

Un juez solo puede proceder a dictar sentencias en casos concretos y nunca extender sus efectos a casos que ni siquiera se han demandado, como se pretende con el estado de cosas. Esto implica dos aspectos: el primero, que se puede generar una supremacía de las demás ramas del poder sobre la judicial, desconociendo su papel como guardián de la Constitución; y el segundo, que se fijan límites a la discrecionalidad judicial, indicando que solo se actúa en casos concretos y que la generalidad, así sea frente a casos estructurales como la masiva infracción de derechos, le corresponde al legislador y al ejecutivo. Lo contrario es una actuación judicial desmedida.

A su vez, la structural remedies, congruente con la declaratoria de un estado de cosas, confía en que los jueces pueden ampararse en la cooperación interinstitucional para resolver graves cuestionamientos de la realidad a la planeación constitucional, lo que puede fomentar un activismo judicial, o para lecturas más severas un gobierno judicial. Bajo esta doctrina, el juez constitucional puede proceder a adoptar medidas estructurales que ayuden a remediar graves infracciones a los derechos fundamentales, vinculando múltiples actores institucionales, revisando la efectividad de las políticas públicas, fomentando el efecto expansivo de la sentencia y vigilando su cumplimiento.

14 Este debate tuvo su máximo desarrollo en Estados Unidos, particularmente en los años cincuenta

15 COLOMBIA. Corte Constitucional. Sentencia SU-913/09. Disponible en: https://www.avancejuridico.com/actualidad/ultimoscomunicados/SU913-09.html. Consultado el 20 oct. 2019. 
Con esto, nuestra teoría se encuentra afín con la doctrina de la structural remedies y la protección objetiva de los derechos, es decir, una visión que supera una protección casuística o subjetiva16; así lo evidencia la definición promovida por el magistrado Henao Pérez en la Sentencia SU-913/0917.

En relación con el concepto de estado de cosas inconstitucional, la jurisprudencia informa que en varias oportunidades la Corte Constitucional ha asumido de manera integral el conocimiento de situaciones que atentan sistemáticamente contra la supremacía de la Constitución y los derechos fundamentales, de manera que para su efectiva protección resulta precaria la adopción de medidas interpartes, dada la entidad y trascendencia de los hechos trasgresores frente a los cuales las medidas deben tener mayor espectro.

Agrega la Corte, reiterando su competencia para fijar acciones estructurales y para expandir los efectos de sus fallos, que:

El uso del concepto de estado de cosas inconstitucional, el cual viene necesariamente acompañado del despliegue de acciones estructurales dirigidas a encauzar la situación anómala dentro los linderos de la Carta; en tales eventos el fallo no restringe sus efectos a aquellos que acuden a la acción de tutela para la protección de sus derechos fundamentales, sino que los extiende a un número indeterminado de personas que se encuentran en las mismas circunstancias de los tutelantes e irradia sus órdenes y efectos a aquellas personas o entidades que tienen en sus manos la facultad o el poder de conjurar la particular situación vulnerante, de forma tal, que la providencia tiene un efecto inter comunis...

\section{LA SEPARACIÓN DE PODERES Y EL CONCEPTO DEL ESTADO DE COSAS INCONSTITUCIONAL}

Lo analizado presenta una confrontación entre la defensa del principio del Estado Social de Derecho y la separación de poderes que la Corte Constitucional ha ponderado a favor de la primacía de la libertad, la participación ${ }^{18}$, la igualdad y la dignidad humana por encima de una lectura formal o apegada a la legalidad de las competencias de los poderes públicos. La Corte procede evaluando la existencia de una vulneración masiva, en muchos casos propiciada por la ineficiente labor del Estado, que omite sus obligaciones, no adopta medidas legislativas, administrativas o presupuestales pertinentes y suficientes para evitar la vulneración de los derechos de una comunidad, lo que, una vez probado, hace que la Corte opte por otorgar la protección congruente con la infracción padecida.

Lo expuesto apareja un reforzamiento de la presunta intromisión de los jueces en asuntos de competencia de otros poderes, pues se valora la gestión pública adelantada, se ordena implementar medidas urgentes, completas y políticas públicas que aseguren el abordaje a largo plazo de la infracción,

16 ALEXY, R. Teoría de los derechos fundamentales. Madrid, España: Centro de Estudios Constitucionales de Madrid, 1997.

17 Henao Pérez en la Sentencia SU-913/09. COLOMBIA. Corte Constitucional. Sentencia SU 913/09. Disponible en: https://www.avancejuridico. com/actualidad/ultimoscomunicados/SU-913-09.html.

18 El ECl también constituye una medida de integración de los excluidos, de los que padecen el apartheid, fomentando el derecho al amparo por parte del estado, el restablecimiento de las capacidades básicas y el desarrollo autónomo del proyecto de vida; pero, además, exige la interacción de las entidades estatales nacionales y territoriales con las víctimas del estado de infracción, fomentando su deliberación y representación. 
Novos Estudos Jurídicos

y controla el cumplimiento de lo dispuesto hasta verificar la superación del estado de cosas. Así, el juez se convierte no en un legislador negativo ${ }^{19}$, efecto propio del control de constitucionalidad sobre las leyes, sino también en uno positivo pues evalúa y requiere acciones legislativas específicas, que cumplan con requerimientos descritos en las sentencias, y posteriormente define si lo desarrollado es idóneo (Sentencia T-025/04, pp.67-80); al mismo tiempo, frente a la administración pública y demás organismos de la estructura estatal, dispone programas y labores adicionales a los que la ley o los estatutos les han impuesto o la interpretación administrativa del alcance de los mismos.

Así, en casos como el del desplazamiento o el hacinamiento carcelario ${ }^{20}$ el juez constitucional ha evaluado la política pública de protección respectiva desde varios ámbitos:

Los datos acerca de la cobertura de cada uno de los componentes de la atención.

El grado de satisfacción de la población afectada.

La capacidad institucional.

Los problemas más sobresalientes de la política.

Su monitoreo y evaluación.

La insuficiencia en la apropiación de recursos.

El requerimiento de una gestión pública efectiva capaz de focalizar y reformular las políticas públicas y obtener recursos ordinarios y extraordinarios para su sostenibilidad.

A este elemento debe añadirse el control judicial de políticas públicas que la Corte Constitucional efectúa sobre las decisiones que exigen el ajuste de las políticas públicas, o la creación de programas o medidas complementarias, con el fin de verificar el cumplimiento de la sentencia ${ }^{21}$.

19 KELSEN, Hans. La Garantía Jurisdiccional de la Constitución. Revista Iberoamericana de Derecho Procesal Constitucional, 2008 , v. 10. 3-46.

20 En esta providencia se declaró el ECI por el hacinamiento y las condiciones indignas de reclusión de las personas privadas de la libertad en las cárceles colombianas. Este estado de cosas no ha sido superado pese al control y vigilancia de la Corte, y a las inversiones del Gobierno, presentando hacinamientos que atentan contra la integridad y dignidad de las personas y compromete la responsabilidad del estado como responsable por su cuidado. COLOMBIA. Corte Constitucional Sentencia T-153/98. Disponible en: https://www.corteconstitucional.gov.co/ relatoria/1998/t-153-98.htm. Consultado el 20 oct. 2019.

21 En el marco de este control judicial a las políticas públicas, la Corte convoca a diversas audiencias para verificar y socializar los informes de avances y resultados, la necesidad de decisiones complementarias, escuchar a las distintas autoridades publicadas convocadas, hasta que se obtenga el convencimiento sobre el control o superación del ECl. 
Acerca del alcance de la declaración del estado de cosas sobre la discrecionalidad de los poderes públicos y de las autoridades públicas en general22, la Corte ha expresado en una de sus sentencias hito que:

Esta decisión respeta las prioridades fijadas por el Legislador y por el Ejecutivo y el experticio de las autoridades nacionales y territoriales responsables que definieron el nivel de sus propios compromisos, pero exige que éstas adopten a la mayor brevedad posible los correctivos que sean necesarios para que dicho estado de cosas inconstitucional sea remediado ${ }^{23}$.

Se está en presencia de una figura atípica, justificada en una discrecionalidad judicial razonada en la primacía de la Constitución y en la vulneración masiva a los derechos fundamentales, todo lo que hace que se consolide un modo de actuación judicial que asciende a precedente judicial. Esto ocurre cuando la Corte Constitucional en ejercicio de su facultad de revisión de las acciones de tutela ${ }^{24}$ se ve avasallada por un cúmulo de acciones de tutela que reclaman la misma protección ante una igual o similar infracción ${ }^{25}$, motivada por agentes estatales, privados e incluso irregulares -como los surgidos del conflicto armado-. Al respecto, puede ser ilustrativo el concepto que Plazas $^{26}$ trae a colación sobre el $\mathrm{ECl}$, en el que incluye de forma determinante la interposición masiva de acciones de tutela:

Cuando concurren la violación masiva de derechos fundamentales, las deficiencias estructurales para su atención y la falta de voluntad de las autoridades estatales, en todo o en parte del territorio nacional, de forma tal, que ante esa situación, se puede generar una gran proliferación de tutelas, con graves consecuencias para la congestión de los despachos judiciales.

En consecuencia, se presenta cuando la ineficiente o ausente ejecución de las funciones del Estado promueve o facilita la transgresión permanente y masiva de los derechos fundamentales de una comunidad, siendo necesaria la concurrencia a instancias del poder judicial ${ }^{27}$ de múltiples entidades para su asunción y superación (Sentencia SU-090/00). Es un tema de obligaciones estatales

22 Por ejemplo, en el caso hito de protección a los desplazados (Sentencia T-025/04) la Corte Constitucional ordenó al Consejo Nacional Para la Atención Integral a la Población Desplazada por la Violencia que asegurará la coherencia entre las obligaciones fijadas por las autoridades competentes y el volumen de recursos efectivamente destinados a proteger los derechos de los desplazados. Asimismo, que si concluía que los compromisos asumidos en la política estatal no podrían ser cumplidos, debía redefinir con la participación de la comunidad desplazada públicamente tales compromisos.

23 COLOMBIA. Corte Constitucional Sentencia T- 025/04. Disponible en: http://siic.mininterior.gov.co/content/sentencia-t-025-de-2004. Consultado el 20 oct. 2019.

24 Los efectos interpartes de un procedimiento constitucional como la tutela, conforme al Decreto 2591 de 1991, se transforman en un efecto expansivo (inter pares, inter comunis e incluso erga omnes) con el propósito de ampliar su margen de protección social, tendente a superar la contrariedad entre el espíritu constitucional y la realidad.

25 En la Sentencia T-025/04, determinante en la consolidación de la figura del ECl, la Corte decidió revisar un promedio de 108 acciones de tutela impetradas por 1150 familias, integradas generalmente por mínimo cuatro miembros.

26 PLAZAS, M. Reflexiones sobre el activismo de la Corte Constitucional de Colombia. En XXI Concurso José Ignacio de Márquez sobre derecho económico. Bogotá: Corporación José Ignacio de Márquez, 2009. p. 55.

27 Aunque la declaración del estado de cosas surge del poder judicial y vincula a múltiples entes estatales, también conlleva un requerimiento a la rama judicial, específicamente a múltiples jueces que no han protegido los derechos de las comunidades sumidas en estas masivas infracciones. 
relacionadas con el orden público, la planeación constitucional y la satisfacción de los derechos constitucionales que requieren reivindicación, o al menos el regreso a un estado de normalidad jurídica y fáctica en el que las personas puedan desarrollar sus capacidades humanas y dejar el estado de carencia extrema.

En los términos de la Corte Constitucional de Colombia, el $\mathrm{ECl}$ constituye ${ }^{28}$ :

Una violación que ha venido ocurriendo de manera masiva, prolongada y reiterada y no es imputable a una única autoridad, sino que obedece a un problema estructural que afecta a toda la política de atención diseñada por el Estado, y a sus distintos componentes, en razón a la insuficiencia de recursos destinados a financiar dicha política y a la precaria capacidad institucional para implementarla.

En este orden de ideas, la Alta Corte ha delineado este concepto aproximadamente desde el año 1997 (Sentencias SU-559/9729 y SU-090/00), identificado esencialmente dos aspectos, que en venideros años serán complementados ${ }^{30}$ : i) cuando se presenta una repetida violación de derechos fundamentales de muchas personas, que pueden entonces recurrir a la acción de tutela para obtener la defensa de sus derechos, y ii) cuando la causa de esa vulneración no es imputable únicamente a la autoridad demandada, sino que reposa en factores estructurales del Estado. Además, lo ha precisado exigiendo que la actuación de las entidades obligadas a concurrir en la solución garantice de forma oportuna y eficaz el llamado mínimo de protección.

Se ha establecido que el mínimo de protección supone evitar toda amenaza que impida el libre ejercicio de los derechos fundamentales a las víctimas de la infracción masiva que se desea superar y, la salvaguarda por parte del estado a la vida, a la dignidad, a la integridad física, psicológica y moral, a la unidad familiar, a la prestación del servicio de salud que sea urgente y básico, a la protección frente a prácticas discriminatorias basadas en su condición de víctimas (Sentencia T-025/04, p.40-42) 31. Y, también, dependiendo de cada caso, este mínimo debe comprender la estabilización económica, entendida como la garantía de contar con opciones de subsistencia digna que permitan en un plazo determinado recuperar la autonomía perdida o reducida por la infracción.

28 COLOMBIA. Corte Constitucional Sentencia T- 025/04. Disponible en: http://siic.mininterior.gov.co/content/sentencia-t-025-de-2004. Consultado el 20 oct. 2019.

29 El caso soporte o estructural del ECl consistió en la protección reclamada por múltiples docentes que no eran afiliados al Fondo de Prestaciones del Magisterio; la sentencia extendió los efectos a todo el país pese a que el caso demandado tuvo origen en dos municipios. En la Sentencia SU-090/00, nuevamente con ponencia del magistrado Eduardo Cifuentes, se declaró el estado de cosas por el no pago de unas pensiones. Lo que evidencia, junto con el caso del hacinamiento carcelario, el rol determinante en la instauración de esta teoría.

30 Los demás aspectos delineados por la Corte serán estudiados en el siguiente apartado.

31 En el caso de la protección a los desplazados, adicionalmente se reconocía el derecho a la educación hasta los quince años para el caso de los niños en situación de desplazamiento. Igualmente, el derecho al retorno y al restablecimiento, que consiste en (i) no aplicar medidas de coerción para forzar a las personas a que vuelvan a su lugar de origen o a que se restablezcan en otro sitio; (ii) no impedir que las personas desplazadas retornen a su lugar de residencia habitual o se restablezcan en otro punto; (iii) proveer la información necesaria sobre las condiciones de seguridad existentes en el lugar de retorno, así como el compromiso en materia de seguridad y asistencia socioeconómica que el Estado asumirá para garantizar un retorno seguro y en condiciones dignas; (iv) abstenerse de promover el retorno o el restablecimiento cuando tal decisión implique exponer a los desplazados a un riesgo para su vida o integridad personal; y (v) proveer el apoyo necesario para que el retorno se efectúe en condiciones de seguridad y los que regresen puedan generar ingresos para subsistir autónomamente. También puede verse RODRíGUEZ, C. (Coord.). Más allá del desplazamiento. Políticas, derechos y superación del desplazamiento forzado en Colombia. Bogotá: Bogotá: Ediciones Uniandes, 2010. 


\section{EL ESTADO DE COSAS INCONSTITUCIONAL COMO UNA DECLARACIÓN JUDICIAL EXCEPCIONAL}

Cabe agregar algunas consideraciones sobre un elemento complementario en la construcción del concepto del ECl: se trata del carácter excepcional. Tratándose de una declaración judicial que busca que se supere en el menor término posible una grave, masiva y persistente infracción a los derechos fundamentales, lo que extiende y a la vez limita la competencia del juez constitucional a la verificación de la satisfacción de los derechos, o el control o superación del ECl, representa también un límite determinante que la declaración solo proceda de forma excepcional; no es en ningún evento un mecanismo principal, tal como se predica de la tutela, ya que de promover su carácter principal sería notorio el desplazamiento de las competencias de los demás organismos estatales, e incluso de las previsiones institucionales de la Constitución que se pretende defender.

Para Rodríguez ${ }^{32}$, el carácter excepcional del ECl es necesario y justificable por varias razones. Al tratarse de una intervención sobre políticas públicas, competencia originaria del ejecutivo y el legislativo, conviene evitar cualquier alteración injustificada de la separación de poderes; asimismo, las facultades de la Corte son limitadas, y más allá del activismo judicial, sean o no efectivas las medidas protectoras del ECl, el tribunal está puesto en prueba y cuestionamiento institucional; $y$, por último, la Corte puede terminar siendo evaluada políticamente, ya que ella hace eso con las políticas y la gestión de los poderes públicos, y así, si sus declaraciones resultan no ser exitosas o de impacto, terminaría sufriendo el mal que trata de contener.

En virtud de lo mencionado, el ECI no puede ser una declaración mediada solo por el activismo judicial o las premisas neoconstitucionales ${ }^{33}$, sino que requiere de un adecuado seguimiento de la doctrina y el precedente constitucional en la materia, adecuadamente probado y justificado constitucionalmente. Debe ser un elemento que actúe como reparación o fomento del diálogo interinstitucional y popular, como un restablecimiento de las garantías democráticas ${ }^{34}$, lo que se convierte en tarea y límite del juez constitucional ${ }^{35}$.

32 RODRÍGUEZ, C. (Coord.). Más allá del desplazamiento. Políticas, derechos y superación del desplazamiento forzado en Colombia. Bogotá: Bogotá: Ediciones Uniandes, 2010.

33 Al respecto, ver CARBONELL, M. y GARCÍA, L. El canon neoconstitucional. Bogotá: Universidad Externado de Colombia, 2013.

34 Rodríguez considera que el $\mathrm{ECl}$ es una figura del constitucionalismo moderno y un elemento impulsado por el constitucionalismo colombiano, pero análogo al estado de excepción regulado en los artículos 212 a 215 de la Constitución, o a las acciones afirmativas, pues lo que se busca es establecer una medida provisional a una situación gravosa, bien la infracción masiva de derechos fundamentales, el orden público, económico, social, ambiental, o la igualdad y no discriminación. RODRÍGUEZ, C. (Coord.). Más allá del desplazamiento. Políticas, derechos y superación del desplazamiento forzado en Colombia. Bogotá: Bogotá: Ediciones Uniandes, 2010.

35 ELY, J. H. Democracia y Desconfianza. Una teoría del control constitucional. Bogotá: Siglo del Hombre Editores, 1997; POST, R. y SIEGEL, R. Constitucionalismo Democrático. Por una reconciliación entre constitución y pueblo. Buenos Aires, Argentina: Siglo XXI Editores, 2013. 


\section{ELEMENTOS PARA LA DECLARACIÓN DE UN ESTADO DE COSAS INCONSTITUCIONAL ALGUNAS CONSIDERACIONES CONTEXTUALES}

Bajo la dogmática y práctica interpretación de la Constitución Política que ha desarrollado la Corte Constitucional, se ha aplicado un nuevo constitucionalismo que pretende garantizar la realización de los derechos constitucionales y responder a las demandas sociales, especialmente de las personas más vulnerables. Así, el ECl se presenta como un instrumento decisional del constitucionalismo democrático y social, pues aunque se apuntala en la discrecionalidad judicial no pretende entablar una supremacía judicial, sino canales deliberativos.

Tanto la rama ejecutiva como la rama legislativa -poderes constitucionalmente llamados a encauzar las demandas de la sociedad civil a través de sus políticas públicas legislativas y gubernamentales- se han mostrado desbordadas y en algunos casos indiferentes frente a los requerimientos sociales, tales como la crisis humanitaria del desplazamiento como resultado del conflicto armado, o el creciente hacinamiento carcelario, situaciones que reducen la dignidad humana y fomentan la desconfianza institucional y la crisis de representatividad (Dahl, 1956, 1999), la marginación y un penoso apartheid institucional. Como lo expone García y Espinosa ${ }^{36}$, se trata del derecho a recibir del Estado un amparo mínimo congruente con los fines esenciales este. El ECI garantiza este derecho: la prerrogativa mínima del Estado al amparo en un caso concreto con el objetivo de salvaguardar la integridad y subsistencia humana.

Por lo que se refiere al rol del poder judicial, bajo el liderazgo de la Corte Constitucional este se ha dirigido a consolidar una jurisdicción social mediante innumerables intervenciones en aspectos relacionados con las políticas públicas ${ }^{37}$, que, como se ha mencionado, al analizar la tensión frente al principio de separación de poderes supone un activismo coyuntural que suple la dimensión política por una dimensión jurídica. Esto genera un cuestionamiento acerca de la legitimidad democrática de los jueces para adoptar estas decisiones que comprometen al Estado y a la sociedad, más cuando el poder judicial posee un déficit democrático ${ }^{38}$ y los derechos deberían ser gestionados directamente por el pueblo, con la participación y la deliberación política39.

De su parte, el poder judicial defiende su actividad en el papel defensor de la Constitución y como contención de las mayorías cuando soportadas en su condición y voluntad pretenden abolir o limitar excesivamente los derechos de las minorías ${ }^{40}$. Así, los jueces no imponen su voluntad, sino la voluntad del pueblo manifiesta en la Constitución como ley superior.

\footnotetext{
36 GARCÍA, M.; ESPINOSA, J. El Derecho al Estado. Los Efectos Legales del Apartheid Institucional en Colombia. Bogotá: Centro de Estudios de Derecho, Justicia y Sociedad DeJuSticia, 2013.

37 ARANGO, R. Derechos, constitucionalismo y democracia. Bogotá: Universidad Externado de Colombia, 2004.p.230-233.

38 TUSHNET, M. ¿Por qué la Constitución Importa?. Bogotá: Universidad Externado de Colombia, 2012; WALDRON, J. Derecho y Desacuerdos. Madrid: Marcial Pons, 2005.

39 KRAMER, L. Constitucionalismo popular y Control de Constitucionalidad. Barcelona: Marcial Pons, 2011.

40 DWORKIN, R. Los Derechos en serio. Barcelona: Ariel Derecho, 1999.
} 
Al respecto, la profesora Mabel Londoño ${ }^{41}$, para el caso de nuestro país, enuncia que:

Si bien está claro que el poder judicial no tiene la legitimidad "democrática" con la que cuentan los poderes políticos, el legislativo y el ejecutivo, entendiendo por tal, la que otorga la voluntad de las mayorías expresada en las urnas, (...) tampoco está claro que bajo la actual crisis del sistema político representativo colombiano, y que parece ser más profunda que en muchos otros países de la región, los órganos mayoritarios se encuentren en mejor posición que el poder judicial, teniendo en cuenta que la legitimidad "democrática" no sólo debe medirse por la voluntad de las mayorías manifestada en un momento eleccionario, sino por el compromiso constante que asumen los representantes para con sus representados.

Frente a esta situación, se encuentra que el juez constitucional fomenta una intervención del estado en el marco de una democracia representativa con graves deficiencias en su calidad ${ }^{42}$, que continúa excluyendo y aislando a los ciudadanos, ya que no se evidencian respuestas institucionales a los problemas más importantes de la vida social. Pero a la par, al no incluir a los ciudadanos en la formulación y evaluación de políticas públicas, tampoco existe responsabilidad ciudadana en su realización. Por ello, para Gargarella ${ }^{43}$, tales sistemas conviven con situaciones de marginación extremas u ofensas gravísimas sobre ciertos sectores sociales.

Agrega el mismo autor que las situaciones de exclusión fomentadas por las fallas del sistema jurídico...

no alcanzan a ser desmentidas por la existencia de algún fallo judicial favorable a algún individuo de bajos recursos; la presencia, en el Congreso, de algún diputado identificado con los intereses de quienes están peor; o algunas imágenes televisivas solazándose con las quejas o miserias de algunos pobres ${ }^{44}$.

Esto también puede hacer pensar que, así como el estado de cosas pretende ser una decisión para resolver problemas estructurales, la existencia misma de la declaración evidencia los vacíos deliberativos y participativos de la democracia, lo que fomenta que no solo debe ser excepcional en pro de una adecuada ponderación entre las fuerzas de los poderes públicos, sino especialmente porque las decisiones y debates estructurales deben ser promovidos por la sociedad.

Ahora bien, después de esta puntual contextualización sobre el ámbito en el que se desenvuelve el juez constitucional garante de la primacía constitucional y promotor del ECl, es pertinente proceder a revisar los criterios jurídicos necesarios para su declaración.

41 LONDOÑO, M. El juez constitucional ante la crisis de legitimidad de los órganos mayoritarios. En A. Botero (Ed.), La cuadratura del círculo. Medellín: Universidad de Medellín, 2012, p. 73.

42 MORLINO, L. \& DIAMOND, L. The Quality of Democracy. Workingpaper, (20). Stanford, USA: Center on Democracy, Development, and the Rule of Law Stanford Institute on International Studies. 2012; MORLINO, L. Democracia y Democratizaciones. Madrid, España: Centro de Investigaciones Sociológicas, 2009.

43 GARGARELLA, R. La coerción penal en contextos de injusta desigualdad. SELA. Recuperado de http://seminariogargarella.blogspot.com/. 2010.

44 GARGARELLA, R. La coerción penal en contextos de injusta desigualdad. SELA. Recuperado de http://seminariogargarella.blogspot.com/. 2010. p.17. 


\section{CRITERIOS JURISPRUDENCIALES PARA LA DECLARACIÓN DE UN ESTADO DE COSAS INCONSTITUCIONAL}

La Corte Constitucional estableció estos criterios entre 1997 y 2004, principalmente mediante las Sentencias SU-559/97 -fundacional del ECI-, T-068/98 y SU-090/00, hasta la expedición de la Sentencia hito T-025/04, declaratoria del ECI por la infracción masiva de los derechos de la población desplazada. A continuación, se pasa al análisis de las respectivas causales, indicando de forma previa que todas deben ser acreditadas para que proceda la declaratoria.

«la vulneración masiva y generalizada de varios derechos constitucionales que afecta a un número significativo de personas», pudiendo incluso extender sus efectos a todas las personas que posean el mismo caso, tal como se presentó en la sentencia SU-559/97, en la que se tacha la política educativa carente de vigilancia y control sobre la afiliación de los docentes al Fondo Nacional de Prestaciones del Magisterio ${ }^{45}$.

«la prolongada omisión de las autoridades en el cumplimiento de sus obligaciones para garantizar los derechos»; como se presentó ante la declaración del hacinamiento carcelario (Sentencia, T-153/98), el desplazamiento forzado (Sentencia T-025/04), el sistema de salud (Sentencia T-760/08), en los que las autoridades públicas presentaron una actuación omisiva y en otros caso ineficiente, trasladando los efectos de su ineficiencia a las personas que debían gozar de protección ${ }^{46}$.

«la adopción de prácticas inconstitucionales, como la incorporación de la acción de tutela como parte del procedimiento para garantizar el derecho conculcado» (sentencia T-025/04, p.82) ${ }^{47}$; en la Sentencia T-068/98 la Corte sanciona la persistente mora en la resolución de las peticiones sobre la concesión de pensiones, y en la exigencia de la interposición de la tutela para acceder al derecho o para que la entidad ejecute la labor pública que le es propia, lo que también se presenta en las solicitudes ante las empresas promotoras de salud.

«la no expedición de medidas legislativas, administrativas o presupuestales necesarias para evitar la vulneración de los derechos» (Sentencia T-025/04, p.82); en las Sentencias SU250/98, T-1695/00 y SU-913/09 se requiere a las entidades públicas respectivas la realización del concurso de méritos para la selección de notarios, omitido persistentemente, lo que afecta el derecho a la fe pública.

«la existencia de un problema social cuya solución compromete la intervención de varias entidades, requiere la adopción de un conjunto complejo y coordinado de acciones y exige un nivel de recursos que demanda un esfuerzo presupuestal adicional importante»48; por ejemplo, en la Sentencia T-068/9849 la Corte expuso:

45 COLOMBIA. Corte Constitucional Sentencia T- 025/04. Disponible en: http://siic.mininterior.gov.co/content/sentencia-t-025-de-2004. Consultado el 20 oct. 2019. p.81.

46 COLOMBIA. Corte Constitucional Sentencia T- 025/04. Disponible en: http://siic.mininterior.gov.co/content/sentencia-t-025-de-2004. Consultado el 20 oct. 2019. p.81-82.

47 Al respecto es diciente la sentencia T-760 de 2008, en la que la Corte hace amplias consideraciones acerca de las infracciones cometidas contra las personas que adelantan trámites ante el sistema de salud. Especialmente por la negativa del reconocimiento de medicamentos extra POS. Se estima para 2008, que de 280.000 tutelas interpuestas cerca de 90.000 , tienen que ver con el derecho a la salud.

48 COLOMBIA. Corte Constitucional Sentencia T- 025/04. Disponible en: http://siic. mininterior.gov.co/content/sentencia-t-025-de-2004. Consultado el 20 oct. 2019. p. 82.

49 COLOMBIA. Corte Constitucional. Sentencia T-068/98. Disponible en: https://www.corteconstitucional.gov.co/relatoria/1998/t-068-98.htm. p.11-12. 
De acuerdo con estadísticas que presenta la misma entidad demandada, durante los años 1995, 1996 y 1997 se instauraron cerca de 14.086 acciones de tutela en contra de la Caja Nacional de Previsión y, si se realiza un cotejo con la totalidad de expedientes de tutela que se remitieron para eventual revisión a esta Corporación en esos años (aproximadamente 94000), se observa como casi un $16 \%$ de todas las tutelas del país se dirigen contra esa entidad. Esto significa que existe un problema estructural de ineficiencia e inoperancia administrativa, lo cual se considera un inconveniente general que afecta a un número significativo de personas que buscan obtener prestaciones económicas a las que consideran tener derecho.

«si todas las personas afectadas por el mismo problema acudieran a la acción de tutela para obtener la protección de sus derechos, se produciría una mayor congestión judicial» ${ }^{50}$, así se presenta en los casos de trámites pensionales, de salud, y en general en los casos del $\mathrm{ECl}$, en los que se promueve la acumulación de acciones de tutela y que sus impactos decisionales sean expansivos.

\section{IDENTIFICACIÓN DE LA CASUÍSTICA DECLARATORIA DEL ESTADO DE COSAS INCONSTITUCIONAL}

Enseguida se hace una precisa descripción de los casos fundacionales de las diversas declaraciones del ECl, desde 1997 a 2015:

1) ECI frente al respeto de las garantías de los docentes. Se da una omisión persistente de las entidades territoriales municipales de afiliar a sus maestros al Fondo Nacional de Prestaciones del Magisterio, pese a retener los salarios devengados para el pago de los aportes. En la sentencia SU559/9751, la corporación manifestó:

La Corte Constitucional tiene la seguridad de que mientras no se tomen medidas de fondo sobre los factores enunciados y los otros que los expertos puedan determinar, el problema planteado, que de suyo expresa un estado de cosas que pugna con la Constitución Política y sujeta a un grupo significativo de educadores a sufrir u tratamiento indigno, se tornará de más difícil solución y propiciará la sistemática y masiva utilización de la acción de tutela.

2) ECI frente al hacinamiento carcelario. A través de la Sentencia T-153/98 se fundó el ECI por el hacinamiento y las condiciones indignas de reclusión de las personas privadas de la libertad en los distintos centros penitenciarios, ordenando a diversos órganos públicos la creación de esquemas de seguimiento y políticas de inversión ${ }^{52}$. Sobre el particular, expresó la Corte:

50 COLOMBIA. Corte Constitucional Sentencia T- 025/04. Disponible en: http://siic.mininterior.gov.co/content/sentencia-t-025-de-2004. Consultado el 20 oct. 2019. p. 82.

51 COLOMBIA. Corte Constitucional. sentencia SU-559/97. Disponible en: https://www.corteconstitucional.gov.co/relatoria/1997/SU559-97.htm.

52 Este estado de cosas aún no superado se ha soportado en otras sentencias de la Corte Constitucional: T-606/98, T-607/98, T-847/00 y T-966/00; T-530/99, T-256/00, T-257/00, T-352/00, T-269/02, T-1030/03, T-848/05, T-693/07, T-971/09, T-804/10, T-825/10, T-062/11 y T-388/13. COLOMBIA. Corte constitucional. Disponible en: https://www.corteconstitucional.gov.co/T-025-04/A2014.php. 
Las cárceles colombianas se caracterizan por el hacinamiento, las graves deficiencias en materia de servicios públicos y asistenciales, el imperio de la violencia, la extorsión y la corrupción, y la carencia de oportunidades y medios para la resocialización de los reclusos. (...) Esta situación se ajusta plenamente a la definición del estado de cosas inconstitucional ${ }^{53}$.

3) ECI frente a la infracción al derecho de petición y al derecho a recibir respuestas oportunas de las entidades de la seguridad social en pensiones. En la Sentencia T-068/98 se declaró el incumplimiento persistente de la Caja Nacional de Previsión en resolver las peticiones presentadas por los pensionados, las cuales comprendían el reconocimiento, reliquidación y pago de las pensiones ${ }^{54}$. La entidad señaló que tenía un retraso de 45000 peticiones y que tardarían dos o tres años para dar respuesta. La Corte consideró que:

El juez constitucional no puede ser indiferente a la situación irregular que se presenta, pues todas las entidades del Estado, lo que incluye a la Caja Nacional de Previsión, son instrumentos al servicio de la comunidad y se instituyen no como fin en sí mismas sino como medio para cumplir con los fines del Estado. Por consiguiente, si una entidad incumple parte de los objetivos para lo que se creó se le impone la necesidad de adecuar su estructura institucional a las nuevas exigencias de la Constitución ${ }^{55}$.

Cabe señalar que en este caso la Corte ha estimado (Sentencias T-068/00 y SU-090/00) ${ }^{56}$ que su labor como guardiana de la supremacía de la Constitución exige adoptar y requerir medidas para superar cualquier agresión o desconocimiento de las directrices constitucionales y lograr su efectividad, al efecto, promoviendo la colaboración armónica entre los poderes públicos y la implementación de las medidas administrativas y financieras necesarias, razones que por sí solas justificaban la declaratoria del ECI.

4) $\mathrm{ECl}$ frente a las persistentes amenazas a los derechos de los defensores de derechos humanos. En la Sentencia T-590/98 se reprocha la reiterada omisión del Estado en adoptar medidas de protección para garantizar los derechos de los defensores de derechos humanos, víctimas de constantes amenazas contra su vida e integridad y la de sus familias ${ }^{57}$. Sobre estos hechos la Alta Corte reafirma el contexto normativo constitucional que legitima su intervención:

Si el Estado cumpliera a cabalidad su deber de prevenir, investigar y castigar las violaciones a los derechos humanos, no surgiría la necesidad de que los particulares se convirtieran en defensores de aquellos derechos. Sin embargo, eso no ocurre, y, además, el artículo 95 de la Constitución Política establece, entre las obligaciones de todas las personas en Colombia, "Defender y difundir los derechos humanos como fundamento de la convivencia pacífica".

53 COLOMBIA. Corte Constitucional. Sentencia T - 153/98. Disponible en: https://www.corteconstitucional.gov.co/relatoria/1998/t-153-98.htm.

54 Otros pronunciamientos de la Corte Constitucional acerca de este ECI: T-439/98, T-274/07, T-525/97, T-1234/08, T-016/10, T-077/10, T-300/10, T-891/10, T-951/10, T-234/11 y T-431/11. COLOMBIA. Corte constitucional. Disponible en: https://www.corteconstitucional.gov.co/T-025-04/ A2014.php.

55 COLOMBIA. Corte Constitucional. Sentencia T-068/98. Disponible en: https://www.corteconstitucional.gov.co/relatoria/1998/t-068-98.htm.

$56 \mathrm{El} \mathrm{ECl}$, frente a la infracción al derecho de petición y al derecho a recibir respuestas oportunas de las entidades de la seguridad social en pensiones, fue complementado en la Sentencia SU-090/00, reiterando el carácter injustificado de cualquier retraso en el pago y reconocimiento de las pensiones.

57 Otros pronunciamientos sobre este caso son: T-558/03, T-1191/04, T-524/05 y T-1037/06. COLOMBIA. Corte constitucional. Disponible en https://www.corteconstitucional.gov.co/T-025-04/A2014.php. 
Obligación que se desprende del propio Preámbulo de la Carta en cuanto la finalidad de la Nueva Constitución es la de "asegurar a sus integrantes la vida, la convivencia, el trabajo, la justicia, la igualdad, el conocimiento, la libertad y la paz". En conclusión, el respeto y defensa de los derechos humanos legitima un Estado Social de Derecho ${ }^{58}$.

5) ECI por la apertura del concurso público de méritos para la selección de notarios públicos. La declaración inicial de este estado de cosas fue hecha en la Sentencia SU-250/9859. En este caso, se identificó que la omisión de convocar un concurso público de méritos no solo desconocía la directriz constitucional del artículo 131, sino que representaba un desconocimiento de los derechos a acceder a los cargos públicos a través de la valoración de los méritos y en consecuencia al debido proceso.

También era manifiesto que las notarías como guarda de la fe pública estaban siendo convertidas en estructuras de interinidad que desconocían el derecho a consolidar una estabilidad laboral, pues bajo tal condición se sometía a los servidores a una lógica burocrática y a una discrecionalidad excesiva que podía negar la objetividad de las garantías laborales. Cuestiones que llevaron al juez constitucional a ordenar la realización de las diligencias necesarias para integrar la carrera notarial. Sobre este caso, dijo la Corte Constitucional:

No hay explicación razonable para que no se convoque a concurso para designación de notarios en propiedad, ya que hay normatividad vigente en lo referente a organismo que administra la carrera y el concurso...como no se ha convocado a concurso para la designación de notarios en propiedad, lo cual ha debido hacerse en toda la República, se llega a la conclusión de que se está dentro de un estado de cosas abiertamente inconstitucional... Y que, es dentro de este contexto que adquiere importancia la calificación que judicialmente se haga de la existencia de un estado de cosas inconstitucional, puesto que ello implica la necesidad de dar órdenes para que cese ese estado de cosas inconstitucional ${ }^{60}$.

6. ECI frente al desplazamiento forzado. La Sentencia T-025/04 (M.P. Manuel José Cepeda) declara la infracción masiva y persistente de los derechos de la población desplazada, sin embargo, este trascendental ECI tuvo antecedente en las Sentencias T-227/97 y SU-1150/0061. Más allá de esto, la Sentencia T-025 es la declaración más contundente que se ha formulado, tanto por el carácter colectivo de la decisión y la totalidad de derechos infringidos como por los efectos de las medidas de amparado dispuestas, las cuales vinculan un amplio número de entidades; todo como una manera de responder a la masiva y estructural crisis humanitaria que ha supuesto el mayor desafío para la vigencia y realización de la Constitución.

58 COLOMBIA. Corte Constitucional. sentencia T 590/98. Disponible en: https://www.corteconstitucional.gov.co/relatoria/1998/T-590-98.htm.

59 En la Sentencia T-1695/00 se declaró la continuidad del ECl por la no convocatoria al concurso de méritos para el nombramiento de notarios. Otras sentencias que desarrollan el caso son: C-373/02, C-076/06, C-421/06, T-634/07, C-177/09 y SU-913/09. COLOMBIA. Corte constitucional. Disponible en: https://www.corteconstitucional.gov.co/T-025-04/A2014.php.

60 COLOMBIA. Corte Constitucional. sentencia SU-250/98. Disponible en: https://www.corteconstitucional.gov.co/relatoria/1998/SU250-98. htm.

61 Conforme a la Sentencia T-025/04, desde 1997 la Corte ya venía reconociendo la gravísima situación de los desplazados en Colombia efectivamente reconociendo derechos como: (i) la igualdad; (ii) la vida e integridad personal; (iii) el acceso efectivo a los servicios de salud; (iv) el derecho al mínimo vital garantizando el acceso a los programas de restablecimiento económico; (v) el derecho a la vivienda; (vi) la libertad de locomoción; (vii) el acceso al derecho a la educación; (viii) los derechos de los niños; (ix) el derecho a escoger su lugar de domicilio; (x) el derecho al libre desarrollo de la personalidad; (xi) el derecho al trabajo; (xii) el acceso a la ayuda humanitaria de emergencia; (xiii) el derecho de petición; y (xiv) el acceso a los programas de ayuda. COLOMBIA. Corte Constitucional Sentencia T- 025/04. Disponible en: http://siic. mininterior.gov.co/content/sentencia-t-025-de-2004. Consultado el 20 oct. 2019. 


\section{ALGUNAS CONSIDERACIONES ACERCA DE LA DECLARACIÓN DEL ESTADO DE COSAS INCONSTITUCIONAL EN MATERIA DE DESPLAZAMIENTO FORZADO INTERNO}

Respecto de esta declaración, la cual constituye un hito en el precedente genérico ${ }^{62}$ del ECl, es pertinente resaltar que la Corte Constitucional asume su estudio partiendo de la premisa de que se trata de un problema humanitario (Sentencia T-227/97) que exige una respuesta integral por parte del Estado y de la solidaridad y entendimiento de la sociedad. Para ello, se vislumbra en la declaración del ECI de la población desplazada, que siendo congruente con el carácter infrahumano e infractor masivo de la condición humana que viven estas personas, que se recurre a la llamada emergencia social como una situación anormal que amerita decisiones excepcionales para retornar al grado más adecuado de normalidad jurídica, en el que se asegure el mínimo vital como ámbito en el cual se pueden superar las carencias que impiden el ejercicio libre de las capacidades humanas.

Lo descrito implica que se parte del reconocimiento de la realidad reflejada en las mediciones sobre la cantidad de población sometida a la condición de desplazamiento, las cuales estimaron que desde 1997 a 2013 habían sido registradas oficialmente 5185406 personas desplazadas internas, así como un total de 2581553 hectáreas bajo solicitud de restitución (Alto Comisionado de las Naciones Unidas para los Refugiados [Acnur], 2013)63. A la vez, La Corte Constitucional (Sentencia T-025/04) ha llegado a fundar sus declaraciones en el reconocimiento de la falta de capacidad de los desplazados para satisfacer sus necesidades humanas básicas, ya que conforme al programa mundial para la alimentación de las Naciones Unidas, para el año 2003 las condiciones básicas de vida, la mayoría población desplazada, era insatisfactoria (92\%), llegando a alcanzar un 80\% de personas en situación de indigencia ${ }^{64}$. Estas referencias -simplemente ilustrativas-, permiten evidenciar cómo el juez constitucional debe acoger criterios materiales para valorar el carácter masivo y la dimensión de la infracción y, en consecuencia, el grado de su intervención a través de órdenes correctivas al verificar la baja efectividad de la política pública.

62 Se hace referencia a que el ECl constituye un precedente genérico, pues se trata de una teoría jurisprudencial con una serie de requisitos que deben establecerse para poderse aplicar. A la par, está acompañado de precedentes específicos relacionados con los casos concretos que han materializado el ECl y que lo seguirán nutriendo hasta que se declare por el juez constitucional su superación, evento necesario para probar la necesidad y pertinencia de la actuación judicial.

63 Estos datos también reflejan un fuerte impacto en la población afrocolombiana y las comunidades indígenas. Asimismo, conforme a la Acnur, mientras que en el 2007 el $25 \%$ de las tasas de expulsión se concentraba en diecisiete municipios, en el 2013 solo diez municipios (Buenaventura, Medellín, Tierralta, Suárez, Ricaurte, Riosucio, López de Micay y Puerto Asís) concentraron el 50\%. Los tres departamentos con la concentración más alta de eventos de desplazamientos masivos durante el 2013 son Nariño, Antioquia y Chocó (Costa Pacífica). La mayoría de los desplazados internos son desplazados de zonas rurales a centros urbanos, aunque los desplazamientos intraurbanos también están en aumento, ya que el $51 \%$ de los desplazados internos residen en las veinticinco ciudades principales de Colombia.

64 Los datos en que se apoya la Corte Constitucional (Sentencia T-025/04) también incluyen el grado de acceso a la educación de la población escolar desplazada, en el que se reconoce que el $25 \%$ de los niños y niñas entre 6 y 9 años no asiste a un establecimiento escolar, mientras que esta proporción para las personas entre 10 y 25 años es del 54\%. En relación con la salud de las víctimas del desplazamiento la tasa de mortalidad era en el 2004 seis veces superior al promedio nacional. COLOMBIA. Corte Constitucional Sentencia T- 025/04. Disponible en: http://siic.mininterior.gov.co/content/sentencia-t-025-de-2004. Consultado el 20 oct. 2019. 
De acuerdo con lo expuesto, la jurisprudencia constitucional ha reconocido varios elementos que confirman la existencia de un ECI respecto de la población internamente desplazada, tales como: (i) la gravedad de la situación de vulneración de derechos que enfrenta la población desplazada fue expresamente reconocida por el mismo legislador al definir la condición de desplazado, y resaltar la violación masiva de múltiples derechos; (ii) el elevado volumen de acciones de tutela presentadas por los desplazados para obtener las distintas ayudas y el incremento de las mismas; (ii) los procesos acumulados en sentencias como la T-025/04 señalan que la vulneración de los derechos afecta a buena parte de la población desplazada, en múltiples lugares del territorio nacional y que las autoridades han omitido adoptar los correctivos requeridos; (iv) la continuación de la vulneración de tales derechos no es imputable a una única entidad; (v) la vulneración de los derechos de los desplazados reposa en factores estructurales, como la falta de correspondencia entre lo que dicen las normas y los medios para cumplirlas; y (vi) la insuficiencia de recursos destinados por el ejecutivo y legislador frente a la notoria y persistente evolución del problema de desplazamiento; condiciones que reducen la capacidad de respuesta del Estado de Derecho a los fenómenos de la realidad y doblegan la fuerza normativa de la Constitución.

Pero también la Corte constató que la política pública sobre desplazamiento forzado (Ley 387 de 1997), expresada en diversas normas, no produjo los resultados mínimos necesarios, pues la atención humanitaria de emergencia no ha sido suficiente, así como los programas de estabilización socioeconómica o de acceso al mercado laboral; los planes de vivienda no cumplen con las condiciones necesarias de acceso a servicios públicos domiciliarios, ubicación, calidad de los materiales y distribución de los espacios, lo que muestra que el evaluador judicial de la política pública concluye la incapacidad institucional del Estado para afrontar el fenómeno del desplazamiento y la necesidad de un esfuerzo presupuestal para que las medidas tengan impacto directo en la garantía de los derechos de las víctimas.

Así, la Corte, actuando como evaluadora de la política pública, determina, entre varios aspectos, que la política de protección a la población desplazada tuvo serios yerros estructurales en su diseño y reglamentación, dado que no se tenía un plan de acción y de monitoreo a la política pública, de medición de su alcance (plazos y objetivos), metas, prioridades e indicadores, instrumentos necesarios para establecer y valorar sus resultados. Asimismo, no se contaba con una coordinación efectiva y una distribución de responsabilidades claras, puesto que formalmente se contaba con un sistema de atención prioritaria a la población desplazada, pero tal sistema no poseía un nivel de articulación operativo entre el sistema y las entidades territoriales, haciendo explícita la ausencia de talento humano especializado para la implementación y ejecución de la política, en parte por la ausencia de apropiaciones presupuestales. 
Este control judicial a la política pública, como efecto del ECl, igualmente se enfocó en el principio democrático, promoviendo que incluso la generación y ejecución de una política de protección a los derechos excluyeran a las víctimas, reduciendo su poder de participación, deliberación y acceso al estado ${ }^{65}$. Por ello, se requirió de la participación de la población desplazada en el diseño y la ejecución de las políticas en diversos ámbitos territoriales y de acceso a la información oportuna y completa acerca de sus derechos, oferta, procedimientos y requisitos para acceder a ella, así como los responsables de su desarrollo. De la misma forma, se requirió que los funcionarios se encontraran capacitados según sus funciones y responsabilidades para con la comunidad desplazada, lo que amerita un enfoque de respeto y sensibilidad con sus condiciones de vulnerabilidad y diversidad.

Otro criterio trascendental en este caso es el criterio de la urgencia y la prioridad en la atención humanitaria, lo que llevó al juez constitucional a establecer plazos de cumplimiento y verificación, lo que es perentorio pues se necesita abandonar en el menor término posible la situación que se sanciona a través de la intervención judicial. Posterior a esto, es decir, a la verificación de que el estado de cosas no ha sido superado, la Corte complementó su rol como evaluador de políticas públicas con uno de vigilancia y seguimiento a resultados de verificación de la garantía de los derechos, como lo exige la filosofía de la acción de tutela ${ }^{66}$.

De la misma forma, fue contundente la fortaleza judicial para exigir los ajustes presupuestales necesarios para dotar a la política pública y a las órdenes constitucionales de fuerza de realización. Se estimó que era imperioso asegurar los recursos primordiales para la satisfacción de los derechos constitucionales como medida proporcional y congruente con el estado de emergencia que suponía el desplazamiento, pues lo contrario sumiría indefinidamente en condiciones indignas de vida a las víctimas de este flagelo social responsabilidad del Estado. La Corte también amparó su exigencia presupuestal en la prioridad del gasto público social sobre cualquier otra asignación ${ }^{67}$ y en su carácter urgente y prioritario ${ }^{68}$, viendo así que el gasto que implique la protección de las víctimas del desplazamiento forzado es una respuesta humanitaria a una situación infrahumana.

Con esto, la Corte exige el cumplimiento inaplazable de los deberes constitucionales a cargo de diversas entidades nacionales y territoriales encargadas de la atención de la población desplazada, para que aseguren las apropiaciones presupuestales necesarias. Estipula el tribunal constitucional

65 GARCÍA, M. y ESPINOSA, J. El Derecho al Estado. Los Efectos Legales del Apartheid Institucional en Colombia. Bogotá: Centro de Estudios de Derecho, Justicia y Sociedad DeJuSticia, 2013; ACEMOGLU, D. y ROBINSON, C. Por qué fracasan los países. Los orígenes del poder, la prosperidad y la pobreza: Bogotá: Editorial Deusto, 2013.

66 Fruto de este control judicial de políticas públicas desde el año 2004 la Corte Constitucional continúa expidiendo autos cuyo objeto es la verificación del cumplimiento de los deberes impuestos a diversas entidades estatales para la satisfacción de los derechos de la población desplazada. ARANGO, R. Derechos, constitucionalismo y democracia. Bogotá: Universidad Externado de Colombia, 2004; ARANGO, R. El concepto de los derechos sociales fundamentales. Bogotá: Legis, Universidad Nacional de Colombia, 2005.

67 COLOMBIA. Constitución política de Colombia 1991. Art. 350. Disponible en: https://www.corteconstitucional.gov.co/inicio/Constitucion\%20 politica\%20de\%20Colombia.pdf.

68 COLOMBIA. Ley 387 de 1997. Disponible en: https://www.lexbase.co/leyes/indice/1997/387. 
que al intervenir en la planeación financiera de las entidades públicas no desborda la separación de poderes:

Al ordenar este tipo de medidas, no está la Corte desconociendo la separación de poderes que establece nuestra Constitución, ni desplazando a las demás autoridades en el cumplimiento de sus deberes; ...No se trata en este caso de que a través de la acción de tutela se esté ordenando un gasto no presupuestado o que se esté modificando la programación presupuestal definida por el Legislador. Tampoco está definiendo nuevas prioridades, ni modificando la política diseñada por el Legislador y desarrollada por el Ejecutivo. (Sentencia T-025/04)

La visión del ente judicial es que tal intervención es imprescindible para fomentar el principio constitucional de colaboración armónica entre las distintas ramas del poder público, las cuales poseen múltiples obligaciones frente a los derechos de la población; promoción que relata una competencia del juez constitucional en un Estado Social. Se asume la premisa según la cual el juez no puede observar pasivamente la violación masiva de los derechos humanos o esperar indefinidamente el accionar de las demás ramas del poder público y entidades estatales, sino que, frente a la exclusión y marginación que la inacción estatal genera, debe, con cuidado de no suplantar las competencias constitucionales y legales de estos entes, adoptar las medidas necesarias para que el Estado -como máximo responsable- cumpla sus deberes fundamentales ${ }^{69}$.

Dentro de esos deberes fundamentales la Corte Constitucional identificó particularmente la necesidad de comprender la visión de la libertad no solamente desde un ámbito negativo, sino también positivo o prestacional, en ambos casos regidos por la exigencia de respeto al principio de progresividad, esto es, que todo derecho debe tratar de ser desarrollado en la mayor medida posible ${ }^{70}$, pero que una vez alcanzado un determinado grado de cumplimiento y satisfacción únicamente es tolerable constitucionalmente su avance constante y no su retroceso, lo que debería ser evaluado con severidad. Bajo este límite, se identificó el concepto de mínimo existencial o prestacional esencial para la población y a cargo del Estado ${ }^{71}$ :

1. El derecho a la vida.

2. Los derechos a la dignidad y a la integridad física, psicológica y moral.

3. El derecho a la familia y a la unidad familiar.

4. El derecho a una subsistencia mínima como expresión del derecho fundamental al mínimo vital, lo que supone seguridad alimentaria, acceso al agua potable y servicios básicos,

69 Entre tales deberes fundamentales se encuentra el de asegurar el mínimo prestacional de las personas en condiciones de debilidad manifiesta, de las minorías o personas en estado de vulnerabilidad.

70 ALEXY, R. Teoría de los derechos fundamentales. Madrid, España: Centro de Estudios Constitucionales de Madrid, 1997.

71 COLOMBIA. Corte Constitucional Sentencia T- 025/04. Disponible en: http://siic.mininterior.gov.co/content/sentencia-t-025-de-2004. Consultado el 20 oct. 2019. 
vivienda (alojamiento, arrendamiento social, etc.), vestido, servicios de sanidad, etc. Durante un tiempo razonable y necesario para que la persona se restablezca en sus capacidades humanas básicas.

5. El derecho a la salud para preservar la vida y la integridad de la persona ante situaciones de enfermedad o heridas que les amenacen directamente y prevenir las enfermedades contagiosas e infecciosas.

6. El derecho a la protección frente a prácticas discriminatorias basadas en la condición de desplazamiento, o en otras clasificaciones sospechosas.

7. Para el caso de los niños en situación de desplazamiento, el derecho a la educación básica hasta los quince años.

8. La estabilización socioeconómica de las personas en condiciones de desplazamiento, como la generación o capacitación para el establecimiento de proyectos productivos, o de opciones en el mercado laboral, que puedan promover la participación en el mercado y la autonomía en la asunción del plan de vida.

9. El derecho al retorno y al restablecimiento, lo que supone de las autoridades brindar medidas de seguridad para que una vez sea posible las personas puedan libremente decidir regresar a su lugar de origen.

En síntesis, la interpretación de la Corte en este caso no se basó exclusivamente en el precedente constitucional acerca del $\mathrm{ECl}$, sino en la valoración axiológica y material de las condiciones de disponibilidad y acceso de las personas a bienes y servicios básicos, al igual que de su capacidad para superar la condición de desplazamiento que terminó siendo una causa y equivalencia de la pobreza extrema. En conclusión, la Corte declaró formalmente la existencia de un ECI relativo a las condiciones de vida -capacidades humanas- de la población internamente desplazada.

\section{LA VALORACIÓN DE LA SUPERACIÓN DE UN ESTADO DE COSAS INCONSTITUCIONAL}

Una cuestión central en el estudio del ECI no solo son los fundamentos de su declaración sino también la valoración de su superación, ya que del abandono del estado de emergencia y de ausencia estatal depende en gran parte la legitimidad y confianza en la medida de intervención judicial. Por ello, más allá de que el juez guarde competencia hasta que verifique la satisfacción de los derechos amparados, o de que pueda controlar, evaluar y ordenar reformular las políticas públicas, el ECl debe evidenciar un cambio positivo en la situación fáctica que se interviene, de lo contrario la afectación de la separación de poderes, o los llamados a la cooperación armónica interinstitucional, no se justificarán y podrían terminar incrementando la objeción democrática al activismo del juez, pese a su justificación dogmática en la primacía de los derechos y de la Constitución. 


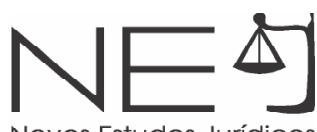

Resulta útil encontrar elementos que permitan evaluar a la sociedad abierta de intérpretes ${ }^{72}$, y especialmente a su evaluador judicial, la efectividad del estado de cosas para superar la infracción masiva reprochada en un caso concreto, esto independientemente de las pruebas de proporcionalidad que se establezcan ${ }^{73}$ y con el fin de definir la prevalencia del núcleo esencial y material de los derechos constitucionales. Ciertamente, la propuesta de Rodríguez ${ }^{74}$ es significativa, pues expone opciones valorativas y racionales de la facticidad que se trata de controlar, razón por la cual se hará una exposición del denominado test de superación del ECl.

El test se presenta como un conjunto de preguntas organizadas de forma lógica que orientan la argumentación, un grupo de indicadores precisos, que sean suficientes, pertinentes y adecuados, y criterios razonables para aplicar dichos indicadores al caso concreto ${ }^{75}$. Bajo este concepto se propone el TESE en cinco asos:

\section{PASO 1: FIJACIÓN DEL TIPO DE INDICADORES PERTINENTES PARA MEDIR LA SUPERACIÓN DEL ECI}

En un primer paso, se requiere la estandarización de criterios de evaluación del ECl. Empero estos criterios no pueden ser una solo lista de parámetros, pues, aunque ayuda a hacer evidente el razonamiento judicial, es necesario que respondan a las especificidades de cada caso, dándose que unos serán los parámetros en el caso de los desplazados y otros en el caso del hacinamiento carcelario. Rodríguez ${ }^{76}$ indica que bajo la perspectiva de los indicadores sobre la protección a los derechos humanos, se debe contar con indicadores de evaluación de proceso y resultado (goce efectivo de derechos, complementarios y sectoriales $)^{77}$. Adicionalmente, se proponen como criterio los indicadores de proceso, siguiendo la línea de evaluación de la Sentencia T-025, los relativos al diseño, la ejecución, la evaluación y la financiación de las políticas públicas.

Lo anterior revela que el test pretende racionalizar la intervención de los jueces en la medición de la gestión del ejecutivo y legislativo, pero en caso de ser necesario ordenar medidas de ajustes presupuestal o de reformulación de políticas públicas, como ejemplos, el juez debe ser transparente y objetivo con los criterios de evaluación, dado que todo parte de la premisa según la cual una evaluación integral a las causas infractoras de los derechos constitucionales y que desconocen

72 HABERLE, P. El Estado Constitucional. Ciudad de México: Universidad Autónoma de México, 2003. p. 82.

73 ALEXY, R. Teoría de los derechos fundamentales. Madrid, España: Centro de Estudios Constitucionales de Madrid, 1997.

74 RODRÍGUEZ, C. (Coord.). Más allá del desplazamiento. Políticas, derechos y superación del desplazamiento forzado en Colombia. Bogotá: Bogotá: Ediciones Uniandes, 2010.

75 RODRÍGUEZ, C. (Coord.). Más allá del desplazamiento. Políticas, derechos y superación del desplazamiento forzado en Colombia. Bogotá: Bogotá: Ediciones Uniandes, 2010. p. 476.

76 RODRÍGUEZ, C. (Coord.). Más allá del desplazamiento. Políticas, derechos y superación del desplazamiento forzado en Colombia. Bogotá Bogotá: Ediciones Uniandes, 2010.

77 En lo expuesto se siguen los criterios de la Corte Constitucional asumidos en los Autos 109/07 y 233/07 y el Auto 116/08, y la división de los indicadores de resultado, entre indicadores de goce efectivo de derechos, complementarios y sectoriales. 
la vigencia de la Constitución requieren de una contundente argumentación y una deliberación interinstitucional e interdisciplinaria. Valga decir, aunque el juez puede seleccionar los criterios del paso 1, estos deben ser validados en el diálogo social y en la interacción con los distintos órganos participantes en el juicio constitucional. Esto es necesario debido a que no puede promoverse la persistencia de decisiones judiciales que son la simple expresión del discernimiento judicial, sino que deben ser validadas y consideradas en un ambiente democrático, lo cual es trascendental tratándose de decisiones de alto impacto social y estatal.

\section{PASO 2: FIJACIÓN DE LA LISTA DE INDICADORES DENTRO DE CADA DI- MENSIÓN (PROCESO Y RESULTADO)}

Con base en una propuesta de indicadores definidos en los casos de desplazamientos y el seguimiento a los casos de las poblaciones femenina, indígena y afrodescendientes que ha padecido este flagelo, se toma una propuesta de indicadores -veinte en total- que permiten evaluar integralmente una política en particular que resulte insuficiente para satisfacer los derechos violados y que en todo caso impactara las cuatro dimensiones de la política pública: diseño, ejecución, seguimiento y financiación ${ }^{78}$.

En tal propuesta se aprecian indicadores en la fase de revisión del diseño de la política, tales como la flexibilidad de la regulación de las políticas pertinentes para atender de manera oportuna y suficiente las demandas de la población desplazada, y la existencia del enfoque diferencial en el diseño de las políticas, en relación con: (i) mujeres, (ii) minorías étnicas, (iii) menores, (iv) personas con discapacidad, (v) líderes de organizaciones, y (vi) otros grupos vulnerables.

En lo referente al seguimiento y evaluación, se observa la existencia de sistemas de evaluación de la política de atención a la población desplazada y la disponibilidad de líneas de base sobre las condiciones de vida y el goce de cada uno de los derechos a los que hace referencia la Sentencia T-025/04. Y, en el ámbito de financiamiento, se contempla el nivel de suficiencia de los montos asignados para: (i) satisfacer la demanda de las personas desplazadas; (ii) proteger los derechos fundamentales de las víctimas de este fenómeno; y (iii) desarrollar e implementar efectivamente las políticas previstas en la ley y desarrolladas por el ejecutivo.

Estos indicadores deben ser construidos para cada caso del ECl, pues solo desde el caso concreto puede estimarse el grado de medición y en consecuencia de superación; únicamente así puede procederse a, como lo propone Rodríguez, (i) valorar el peso relativo de la dimensión de proceso y la dimensión de resultado, (ii) calificar los avances en cada indicador, y (iii) determinar si

78 RODRÍGUEZ, C. (Coord.). Más allá del desplazamiento. Políticas, derechos y superación del desplazamiento forzado en Colombia. Bogotá: Bogotá: Ediciones Uniandes, 2010. p.481-483. 


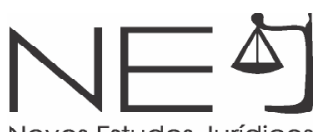

se ha superado el $\mathrm{ECl}$, que son los pasos que siguen en el test y que muestran la relevancia y alcance del rol del juez como evaluador de política pública y autoridad capaz de determinar la superación del $\mathrm{ECl}$.

\section{PASO 3: DETERMINACIÓN DEL VALOR DE LAS DIMENSIONES DE PROCESO} Y DE RESULTADO

En este factor, que supone el estudio detenido de los instrumentos que definen el proceso y los medios utilizados para satisfacer los derechos, tanto de forma inicial -lo contemplado por el legislador y el ejecutivo- como posterior a la intervención judicial con la declaración del estado de cosas -asimismo, los resultados o el impacto de esos medios en la superación de las infracciones masivas-, requiere la asignación de valores relativos que faciliten medir los avances conseguidos. Se estima que debe darse un valor a cada indicador que se utilice, definiendo si se otorga un mayor peso al proceso o a los resultados ${ }^{79}$, frente a lo cual no debería existir duda ya que la justificación central del $\mathrm{ECl}$ es reprochar y coadyuvar a transformar la realidad infractora de los derechos, por lo que más allá de la pertinencia de los medios, lo que es necesario y exigible, lo más requerido es contar con resultados de impacto que relaten un cambio positivo en la realidad y exigibilidad de los derechos.

Por encima de asignar una valoración específica a los indicadores de proceso y resultado para la superación del ECl, es indispensable evaluar bajo relaciones e instrumentos de proporcionalidad, razonabilidad y efectividad, si se han alcanzado las metas establecidas y si las órdenes constitucionales han sido satisfechas y han cumplido con su cometido; es más adecuado no solo medir sino también establecer relaciones probatorias y deliberativas que acrediten un avance en la superación de las infracciones constitucionales.

\section{PASO 4: CALIFICACIÓN DE LOS INDICADORES DENTRO DE CADA DIMENSIÓN}

En el paso 3 se asignan valores genéricos para los indicadores globales de proceso y resultados, en tanto que en el presente paso deben asignarse para cada indicador que desarrolle estas categorías según el máximo otorgado. Respecto de los derechos en colisión, abolidos o limitados deben ser estudiados en la relación de resultado o satisfacción bajo relaciones materiales y de proporcionalidad, garantizando su igual consideración y jerarquía, por lo que deben contar con la misma valoración, e igualmente se debe proceder por razones instrumentales con las variables de proceso, salvo que exista alguna particularidad o razón constitucional importante; por ejemplo, si se crearon los procesos y mecanismos de participación de las comunidades afectadas, cuestión que aunque refleja algo sustancial exige un procedimiento idóneo.

$79 \quad$ Rodríguez expone que existen diversas alternativas para la Corte, según la ponderación que establezca, bien el $60 \%$ de la calificación de superación del ECl a la dimensión de resultado y $40 \%$ a la de proceso, o un 80/20, por indicar algunos ejemplos. RODRíGUEZ, C. (Coord.). Más allá del desplazamiento. Políticas, derechos y superación del desplazamiento forzado en Colombia. Bogotá: Bogotá: Ediciones Uniandes, 2010. p. 483. 
Alternamente se propone tener en cuenta, y con un puntaje que revele su grado de importancia, (i) los grados de protección o de goce efectivo de los derechos ${ }^{80}$, (ii) los indicadores complementarios ${ }^{81}$ y (iii) los sectoriales ${ }^{82}$. También debe tenerse en cuenta no asignar reconocimientos cuando la satisfacción de los derechos no supere niveles aceptables, o mínimos vitales; $y$, aunque generalmente no ha ofrecido detenimiento particular, la variable de sostenibilidad y perdurabilidad en el tiempo de las metas y satisfacciones debe representar un aspecto central y de supervisión por los órganos estatales misionalmente encargados.

\section{PASO 5: FIJACIÓN DEL UMBRAL DE SUPERACIÓN DEL ECI Y CONCLUSIÓN DEL TEST}

Este paso representa un elemento de amplia discrecionalidad para la Corte, pues en ella se concentra la estimación de la gravedad y alcance de los correctivos exigidos y aplicados, lo que hace que exige su adopción a través de procesos de lectura de la realidad, de avance de las decisiones adoptadas y de evaluación conjunta con los demás organismos estatales -lo que se ha tratado de hacer por medio de audiencias de seguimiento y los autos de vigilancia, seguimiento y órdenes complementarias, entre otros elementos-. Así, en esta fase del test se requiere definir un umbral de superación del ECl, siguiendo como criterios las cualidades básicas de los derechos constitucionales, como son su carácter progresivo, inmunidad, inalienabilidad y valor intrínseco, las cuales representan tanto ámbitos mínimos de protección como de restricción para el Estado y los privados, teniéndose que, si estas cualidades no se respetan o se afectan gravemente, el $\mathrm{ECl}$ no puede calificarse como superado ${ }^{83}$.

La construcción de este umbral de superación del ECl debe gozar de una amplia consideración de los valores y principios constitucionales, los deberes fundamentales del Estado y la sociedad frente a los más débiles, de la protección a los mínimos de subsistencia y, a la par, conforme a niveles deliberativos, establecer la responsabilidad de cada ente en la protección de los derechos y en la no tolerancia de umbrales indeseables, lo que en Colombia ha gozado de plena notoriedad (p. ej., caso de los desplazados, hacinamiento carcelario, salud, etc.), legitimando la intervención social de los jueces constitucionales.

80 Los grados de protección o de goce efectivo de los derechos pueden entenderse como aquellas condiciones definidas jurídica y judicialmente como necesarias para que los derechos subsistan o no sean limitados en exceso, pero además apuntan a condiciones de disponibilidad, exigibilidad y protección.

81 Los indicadores complementarios apuntan a aspectos formales y materiales necesarios para que las personas puedan acceder progresivamente a los derechos, al igual que al establecimiento de esquemas o instrumentos no contemplados para asegurar el acceso a los derechos.

82 Los indicadores sectoriales pueden interpretarse como factores que aseguran la inclusión en las políticas públicas y programas estatales de componente territorial, pero adicionalmente de la integración a la política nacional de las entidades territoriales y del elemento local como criterio necesario para asegurar la protección de los derechos en la nación. Esto comprende también la participación de cualquier organismo estatal. RODRÍGUEZ, C. (Coord.). Más allá del desplazamiento. Políticas, derechos y superación del desplazamiento forzado en Colombia. Bogotá: Bogotá: Ediciones Uniandes, 2010. p. 484-485.

83 Estos umbrales se superación del ECI requerirían que cada uno de los derechos obtenga un puntaje o valoración que refleje una satisfacción mínima, o relaciones en que aparezcan limitados admisiblemente para que se declare superado el ECl. Por tanto, si algunos de los derechos (p. ej., vida y salud) tienen un alto nivel de avance, pero otros están considerablemente rezagados (p. ej., educación o reparación), no se declararía la superación del ECI. RODRÍGUEZ, C. (Coord.). Más allá del desplazamiento. Políticas, derechos y superación del desplazamiento forzado en Colombia. Bogotá: Bogotá: Ediciones Uniandes, 2010. p. 485. 


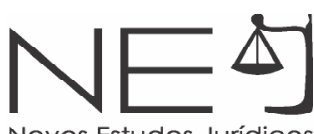

Para Rodríguez ${ }^{84}$ puede ser posible, al estimar los puntajes y valoraciones de cada indicador, establecer los niveles de cumplimiento de los derechos -según el Auto 185/04 de la Corte Constitucional- en niveles: nulo, bajo, medio o alto. Lo que permitiría poder avanzar en la superación del $\mathrm{ECl}$ de forma parcial y no trabajar bajo supuestos de una exigencia desmedida o incoherente con las posibilidades materiales. No obstante, no debe descuidarse la naturaleza de los derechos en debate y las implicaciones prácticas que ello demanda, lo que no impediría hacer un análisis de contexto social que le facilite al juez establecer niveles tolerables de protección de los derechos y que pueda avalar parcialmente, sin que por ello pierda su vigilancia como garante judicial si en un caso determinado las infracciones persisten.

El juez constitucional debe proceder siempre rechazando los niveles extremos, o sea, ni puede avalar protecciones simplemente formales o nulas, pero debe evaluar integralmente su legitimidad para requerir satisfacciones de alto grado, no porque no sean justificables constitucionalmente, sino porque muchas de ellas se construyen y desarrollan democráticamente con el trabajo de los poderes públicos. Por ello, el juez debe evaluar las satisfacciones intermedias para definir su admisibilidad (cargas de argumentación) y proporcionalidad, según afectaciones graves, medias o leves ${ }^{85}$. Estos elementos pueden facilitar que el juez responda con una mejor sensibilidad al establecimiento de un umbral de superación, buscando la razonabilidad y el equilibrio democrático y constitucional más allá de las mediciones ${ }^{86}$, ya que debe ser un objetivo central de la actividad judicial superar la descomposición fáctica y social que supone el ECl.

\section{UN ELEMENTO DELIBERATIVO A CONSIDERAR}

Finalmente, pese a los pasos analizados pertenecientes al test de superación del $\mathrm{ECl}$, convendría profundizar en un complemento relacionado con práctica económica, especialmente con las posibilidades materiales o de disponibilidad de recursos para asumir las medidas correctivas dispuestas por el juez constitucional, en particular como una acción argumentativa y deliberativa frente a los demás poderes públicos. Cabe resaltar que le corresponderá al juez examinar y rebatir si la negativa a ejecutar esfuerzos presupuestales es adecuada, y más cuando se guía por principios como la prevalecía del interés general sobre el particular y en el bienestar general. Se propone un esfuerzo deliberativo que involucre en la declaración del $\mathrm{ECl}$ y su evaluación los argumentos financieros de los obligados a sanear la infracción constitucional, lo que es congruente con la exigencia de consideración y equilibrio fiscal y no pretende menguar la primacía de los derechos y de la propia Constitución.

\footnotetext{
84 RODRÍGUEZ, C. (Coord.). Más allá del desplazamiento. Políticas, derechos y superación del desplazamiento forzado en Colombia. Bogotá: Bogotá: Ediciones Uniandes, 2010.

85 ALEXY, R. (2002). Epilogo a la teoría de los derechos fundamentales. Revista Española de Derecho Constitucional, 2002.66.

86 Rodríguez propone, sin alejarse de la proporcionalidad y la evaluación de las condiciones concretas, que el umbral de superación del ECI sea un nivel alto, esto es, cuando el puntaje global alcance por lo menos las dos terceras partes del puntaje posible (66/100), criterio que ha sido acogido por la Corte en el Auto 185/04.
} 
Esta labor es un ejercicio deliberativo deferente frente a las razones de los órganos de los cuales se busca el restablecimiento de los derechos, haciendo que las decisiones del juez no solo se basen en su función constitucional o en el carácter contramayoritario de los derechos fundamentales, sino en la construcción de un constitucionalismo más democrático ${ }^{87}$ que promueva la participación y la apreciación de las razones de todos los actores sociales; asimismo, que busque el convencimiento y no el autoritarismo judicial en pro de la aceptación de la moralidad política que conlleva la axiología constitucional como pauta de control y origen de las políticas públicas y de la actividad estatal ${ }^{88}$.

Por lo que se refiere al juez, siempre conviene a este contemplar y exigir que se pruebe la ausencia de medios alternativos idóneos para satisfacer los derechos; el poder público debe tener un punto excepcional de inflexión que posibilite responder a los excesos y matices de la realidad sin alejarnos de la racionalidad de la estructura económica, como lo ha probado el doloroso caso del desplazamiento forzado. Pero así como se pide responder a lo excepcional y urgente de un estado de cosas, si la administración posee o puede obtener un medio alterno e idóneo para cumplir con la orden de protección constitucional, es menester del juez sopesarlo, o al menos construir una opción dialógica, lo que modula la discrecionalidad y la evidencia como un constructo de razonamiento.

\section{CONCLUSIONES}

Es de destacar que el $\mathrm{ECl}$ como una posibilidad de adjudicación puede representar un hilo conductor entre la población que afronta una infracción a sus derechos constitucionales y el poder público, capaz de optimizar el principio de colaboración armónica entre las ramas del poder público y el deber de protección efectiva a la población. El ECI se muestra como un complejo y excepcional llamado del poder judicial, principalmente a los ejecutores institucionales e incluso a los privados para que corrijan las actuaciones y situaciones contrarias a la realidad constitucional.

Para emitir ese llamado, el juez debe implementar un examen de los derechos en conflicto, identificar su peso, generar una síntesis y reconocer los consensos y disensos necesarios para garantizar la reparación de las víctimas y los derechos de la minorías como garantía de una democracia social, esto bajo una óptica que garantice la defensa de la axiología humanista constitucional. Sin embargo, es un reto constante y una prueba existencial para el juez revisar que sus decisiones no sofoquen la democracia o anulen o subordinen a los representantes populares, como órganos que han recibido encargos directos del poder constituyente, esto es, por la misma Constitución que faculta al juez para actuar.

87 POST, R. y SIEGEL, R. Constitucionalismo Democrático. Por una reconciliación entre constitución y pueblo. Buenos Aires, Argentina: Siglo XXI Editores, 2013.

88 No es excluyente que las Cortes Constitucionales promuevan el cambio social a través de sus fallos y, a su vez, la deliberación; de hecho, son dos instrumentos necesarios para que dichos cambios sean realmente democráticos y materiales. Al respecto, ver: RODRíGUEZ, C. y RODRÍGUEZ, D. Cortes y cambio social. Cómo la Corte transformo el desplazamiento forzado en Colombia. Bogotá: DeJuSticia, 2010. 
Lo mencionado exige entender que el ECl es un instrumento excepcional, de emergencia, que busca el retorno a la normalidad jurídica y la no reductibilidad de la Constitución a la realidad; en otros términos, busca que prime la supremacía de la Constitución y su fuerza normativa como cualidades que describen su existencia e impacto en la sociedad, por lo que la superación del estado de cosas es trascendental, para la vigencia de la norma que reglamenta el sistema jurídico-político y principalmente para la exigibilidad de los derechos de la población.

No se trata el ECl de una solución deseable, de un resurgimiento de un gobierno de los jueces, se trata del deber constitucional de un poder público de advertir a los demás órganos el imperioso cumplimiento de sus deberes, de corregir las acciones u omisiones que afectan masiva y persistentemente la integridad y dignidad de la población; es un mecanismo de advertencia a los órganos competentes para que dinamicen sus estructuras conforme a la realidad y las disposiciones axiológicas de la Constitución Política. Por ello, la exigencia de sistematizar y comprender los requisitos de aplicación de esta figura y los alcances de su declaración y evaluación.

\section{REFERENCIA DE LAS FUENTES CITADAS}

ACEMOGLU, D. y ROBINSON, C. Por qué fracasan los países. Los orígenes del poder, la prosperidad y la pobreza: Bogotá: Editorial Deusto, 2013.

ALEXY, R. Teoría de los derechos fundamentales. Madrid, España: Centro de Estudios Constitucionales de Madrid, 1997. ALEXY, R. (2002). Epilogo a la teoría de los derechos fundamentales. Revista Española de Derecho Constitucional, 2002. 66.

ARANGO, R. Derechos, constitucionalismo y democracia. Bogotá: Universidad Externado de Colombia, 2004.

ARANGO, R. El concepto de los derechos sociales fundamentales. Bogotá: Legis, Universidad Nacional de Colombia, 2005.

BÖCKENFÖRDE, E. W. Escritos sobre derechos fundamentales. Baden-Baden, Alemania: Nomos Verlagsgesellschaft, 1993.

CARBONELL, M. y GARCÍA, L. El canon neoconstitucional. Bogotá: Universidad Externado de Colombia, 2013.

COLOMBIA. Constitución política de Colombia 1991. Disponible en: https://www.corteconstitucional.gov.co/inicio/ Constitucion\%20politica\%20de\%20Colombia.pdf.

COLOMBIA. Corte Constitucional Sentencia T- 025/04. Disponible en: http://siic.mininterior.gov.co/content/sentencia-t025-de-2004. Consultado el 20 oct. 2019.

COLOMBIA. Corte Constitucional Sentencia T-153/98. Disponible en: https://www.corteconstitucional.gov.co/ relatoria/1998/t-153-98.htm. Consultado el 20 oct. 2019.

COLOMBIA. Corte constitucional. Disponible en: https://www.corteconstitucional.gov.co/T-025-04/A2014.php.

COLOMBIA. Corte Constitucional. Sentencia SU-250/98. Disponible en: https://www.corteconstitucional.gov.co/ relatoria/1998/SU250-98.htm. 
COLOMBIA. Corte Constitucional. Sentencia SU-559/97. Disponible en: https://www.corteconstitucional.gov.co/ relatoria/1997/SU559-97.htm.

COLOMBIA. Corte Constitucional. Sentencia SU-913/09. Disponible en: https://www.avancejuridico.com/actualidad/ ultimoscomunicados/SU-913-09.html. Consultado el 20 oct. 2019.

COLOMBIA. Corte Constitucional. Sentencia T - 153/98. Disponible en: https://www.corteconstitucional.gov.co/ relatoria/1998/t-153-98.htm.

COLOMBIA. Corte Constitucional. Sentencia T 590/98. Disponible en: https://www.corteconstitucional.gov.co/ relatoria/1998/T-590-98.htm.

COLOMBIA. Corte Constitucional. Sentencia T-068/98. Disponible en: https://www.corteconstitucional.gov.co/ relatoria/1998/t-068-98.htm.

COLOMBIA. Ley 387 de 1997. Disponible en: https://www.lexbase.co/leyes/indice/1997/387.

DWORKIN, R. Los Derechos en serio. Barcelona: Ariel Derecho, 1999.

ELY, J. H. Democracia y Desconfianza. Una teoría del control constitucional. Bogotá: Siglo del Hombre Editores, 1997.

GARCÍA, M. y ESPINOSA, J. El Derecho al Estado. Los Efectos Legales del Apartheid Institucional en Colombia. Bogotá: Centro de Estudios de Derecho, Justicia y Sociedad DeJuSticia, 2013.

GARGARELLA, R. La coerción penal en contextos de injusta desigualdad. SELA. Recuperado de http://seminariogargarella. blogspot.com/. 2010.

HABERLE, P. El Estado Constitucional. Ciudad de México: Universidad Autónoma de México, 2003.

HESSE, K. Escritos de Derecho Constitucional. Madrid, España: Centro de Estudios Constitucionales, 1983.

KAFKA, F. Ante la ley. Buenos Aires: Alianza-Emecé, 1976.

KELSEN, Hans. La Garantía Jurisdiccional de la Constitución. Revista Iberoamericana de Derecho Procesal Constitucional, 2008, v. 10.

KRAMER, L. Constitucionalismo popular y Control de Constitucionalidad. Barcelona: Marcial Pons, 2011.

LASALLE, F. J. G. ¿Qué es una Constitución?. Bogotá: Editorial Temis, 2010.

LONDOÑO, M. El juez constitucional ante la crisis de legitimidad de los órganos mayoritarios. En A. Botero (Ed.), La cuadratura del círculo. Medellín: Universidad de Medellín, 2012.

MORLINO, L. \& DIAMOND, L. The Quality of Democracy. Workingpaper, (20). Stanford, USA: Center on Democracy, Development, and the Rule of Law Stanford Institute on International Studies, 2012.

MORLINO, L. Democracia y Democratizaciones. Madrid, España: Centro de Investigaciones Sociológicas, 2009.

PLAZAS, M. Reflexiones sobre el activismo de la Corte Constitucional de Colombia. En XXI Concurso José Ignacio de Márquez sobre derecho económico. Bogotá: Corporación José Ignacio de Márquez, 2009.

POST, R. y SIEGEL, R. Constitucionalismo Democrático. Por una reconciliación entre constitución y pueblo. Buenos Aires, Argentina: Siglo XXI Editores, 2013.

RODRÍGUEZ, C. (Coord.). Más allá del desplazamiento. Políticas, derechos y superación del desplazamiento forzado en Colombia. Bogotá: Bogotá: Ediciones Uniandes, 2010.

RODRÍGUEZ, C. y RODRÍGUEZ, D. Cortes y cambio social. Cómo la Corte transformo el desplazamiento forzado en Colombia. Bogotá: DeJuSticia, 2010. 
SEN, A. Desarrollo y Libertad. Bogotá: Editorial Planeta, 2001.

TUSHNET, M. ¿Por qué la Constitución Importa?. Bogotá: Universidad Externado de Colombia, 2012.

WALDRON, J. Derecho y Desacuerdos. Madrid: Marcial Pons, 2005.

$\Delta$ 